\title{
Teaching Design of Mechanical Professional Knowledge Integration in Petroleum Colleges
}

\author{
Zhang Jianbing ${ }^{1, \mathrm{a}}$, Wang Haiying, ${ }^{1, \mathrm{~b}}$, Wang Haobo ${ }^{1}$, Wang Qian ${ }^{1}$, Kong Detao ${ }^{1}$ \\ ${ }^{1}$ Mechanical Engineering College, Xi'an Shiyou University, Xi'an, Shaanxi, China \\ ${ }^{a}$ zhjb@xsyu.edu.cn \\ b3210208992@qq.com
}

\begin{abstract}
The frontier knowledge of mechanical engineering and petroleum equipment is constantly updated, which puts forward the requirements for increasing the teaching knowledge points of mechanical specialty in petroleum colleges and universities. The certification of engineering education requires the control of theoretical class hours on the premise of student-centered. In order to explore the teaching strategies of mechanical specialty in petroleum industry colleges and universities under this new situation, the new knowledge in the field of mechanical engineering from design, manufacturing to application, and the frontier development trend in the field of petroleum machinery and equipment are combed. Combined with the requirements of the current machinery industry for personnel training, the case teaching method of integrating new knowledge of mechanical engineering into the professional course of petroleum machinery is proposed, and the teaching content is designed. The teaching method of this paper has been practiced and achieved a good effect. It is recognized that the application of case-based teaching method and the integration of new mechanical engineering knowledge into the specialized courses of petroleum machinery specialty can effectively solve the contradiction between the increase of knowledge points and the control of class hours under the new situation, and can train students' ability to comprehensively apply multi-disciplinary knowledge to solve complex engineering problems according to the requirements of professional certification, which is conducive to the cultivation of mechanical engineering talents meet the requirements of industrial development.
\end{abstract}

Keywords : Mechanical engineering, Oilfield equipment, Professional certification, Teaching system

\section{石油院校机械专业知识融合教学设计}

\author{
张建兵 ${ }^{1, a}$ 王海英 $1, \mathrm{~b}$ 王浩博 ${ }^{1}$ 王倩 1 孔德涛 ${ }^{1}$ \\ 1 西安石油大学机械工程学院, 西安, 陕西, 中国 \\ ${ }^{a}$ zhjb@xsyu.edu.cn \\ b3210208992@qq.com
}

\begin{abstract}
摘要
机械工程学科和石油装备前沿知识不断更新, 对石油院校机械专业增加教学知识点提出了要求, 工程教育专业 认证又要求在以学生为中心的前提下控制理论课学时。为了探索这一新形势下石油行业院校机械专业的教学 策略, 梳理了机械工程领域从设计、制造到应用所出现的新知识, 以及石油机械装备领域的前沿发展趋势, 结 合当前机械行业对人才培养的要求, 提出了将机械工程新知识融入石油机械专业课程的案例式教学方法, 并进 行了教学内容的设计。对本文的教学方式进行了实践, 收到了良好的效果。研究认识到, 采用案例式教学方法, 将机械工程新知识融入石油机械特色专业课程, 能够有效解决新形势下知识点增加和控制学时的矛盾, 且能根 据专业认证要求训练学生综合应用多学科知识解决复杂工程问题的能力, 有利于培养适应行业发展要求的机 械工程人才。
\end{abstract}

关键词: 机械工程, 石油装备, 专业认证, 教学系统 


\section{1.引言}

随着先进技术的不断发展，机械工程在设计、仿 真、制造、检测、材料等方面呈现出许多创新性的理 念和技术，同时，石油装备领域也产生诸多前沿知识 [1 2]。针对石油院校的机械类专业学科, 不仅要教授机 械设计制造方面的新知识、新技术，还要教授石油特 色类的机械装备知识, 由此院校提出了增加学时学分 的要求。另一方面, 根据工程教育认证以学生为中心 的理念, 应适当控制学时学分。

由于诸多因素的影响, 以往不少学生的理论学习 和实际问题脱离较为严重, 久而久之学生可能会失去 学习兴趣 $[3]$ 。另外, 学校教学内容比科技发展相对滞 后, 多学科之间的教学内容联系不够紧密, 学生接受 起来较为困难。

针对以上问题，本文将研究探索在石油行业院校 机械专业教学中, 如何解决在不增加学科学时的情况 下, 将机械工程的先进技术和石油行业前沿的新知识、 新技术传授于学生的问题, 从而满足高等教育适应社 会的发展，瞄准行业需求培养人才的目标。

\section{2.机械学科和石油装备新知识分析}

\section{1. 机械工程学科的前沿知识}

机械工程学科以提高人类的利益为目标来研制 和开发新的机械产品, 且在各个行业领域扮演着重要 的角色 ${ }^{[4]}$ 。随着《中国制造 2025》战略的提出以及新 兴的电子计算机科学的蓬勃发展, 机械工程学科与数 学、物理、力学、计算机科学等基础学科联系越来越 广泛，从而使其在设计、制造、检测、材料等方面涌 现出诸多新知识和新技术 ${ }^{[5]}$ 。

在机械设计方面，利用迅速发展起来的计算机技 术、计算技术、应用数学和力学、电子学、测试和分 析技术，使设计技术从经验的、静止的和随意性很大 的传统设计变为基于计算数据、知识工程或专家系统 的、动态的现代设计。从而产生诸多设计方法和技术， 例如计算机辅助设计、模拟仿真与虚拟设计、优化设 计、人工神经网络法、工程遗传算法、并行工程、可 靠性设计、有限元法、模块化设计、相似性设计、智 能设计、创新设计、可靠性设计、精益设计、仿生设 计等新技术 ${ }^{[6]}$ 。

现代制造技术不断吸收优质、高效、低耗的工艺 及加工方法, 不断吸收微电子、计算机和自动化等高 新技术成果, 形成了如先进成形技术、超高速加工技
术、超精密加工技术、快速原型制造技术、敏捷制造、 并行技术、虚拟制造、生物制造等新技术 ${ }^{[7]}$ 。

随着自动化系统规模和新技术应用范围的不断 扩大, 以及学科基础理论和新技术的深入研究, 促进 了机械检测技术的迅速发展 ${ }^{[8]}$ 。从而产生诸多检测方 面新技术，如磁记忆检测方法、声发射检测技术、 TOFD 检测技术等。

机械工程材料知识是机械专业不可或缺的重要 学科基础知识。随着科学技术的进步, 促进了新型材 料的发展，如球墨铸铁、合金铸铁、合金钢、耐热钢、 不锈钢、镍合金、钛合金、硬质合金、高分子工程塑 料、5G 通讯碳基高导热材料、先进碳素及其复合材 料等。

\section{2. 石油装备领域的前沿知识}

随着设计和制造技术的迅速发展，造就了石油装 备的更新换代，同时，伴随着石油开采的环境日渐苛 刻, 相应推动了石油行业关键技术的改革创新, 更为 高端和智能的石油装备层出不穷。新型钻井平台及钻 机如海上钻井平台、海洋石油 981 深水半潜式钻井平 台、直升机升降钻机、快速捼装钻机、极地低温钻机、 12000 米超深井钻机等新装备快速发展。油田专用的 车辆经过集成化、自动化的革新, 涌现出如双机双洜 固井水泥车、 $7000 \mathrm{~m}$ 测井车、联动试井车、背罐车、 自循环洗井车、3000 型压裂车等[9]。另外, 如顶驱装 置、PDC 钻头、碳纤维复合材料连续抽油杆、EILog 测井系统、智能控压钻井系统、智能压裂系统、连续 管测井系统和连续循环系统等新技术及系统也相继 被设计出来。

\section{3.融合前沿知识的特色课程教学内容系统设 计}

为解决教学内容增加和学时减少的矛盾, 本文提 出教学内容上将机械专业课程中先进的设计、制造、 检测、材料技术融入石油特色课程中, 实现学时的优 化利用。在教学方式上采取案例式教学, 提升学生分 析和解决复杂工程问题的能力。

本文对石油院校的机械专业做了教学内容系统 的设计：

（1）机械工程前沿设计方法融入石油特色课程 的教学内容

将现代设计方法融入机械专业石油特色课程中 的教学内容设计如表 1 所示。 
表 1 先进设计技术与石油装备教学知识点融合设计方案

\begin{tabular}{|c|c|c|}
\hline $\begin{array}{l}\text { 机械工程前 } \\
\text { 沿设计方法 }\end{array}$ & $\begin{array}{c}\text { 机械专业课程中石 } \\
\text { 油装备的知识点 }\end{array}$ & 机械工程新知识与石油专业特色课程知识点的融合方法 \\
\hline $\begin{array}{c}\text { 三维造型设 } \\
\text { 计 }\end{array}$ & $\begin{array}{c}\text { 石油专用零件的造 } \\
\text { 型设计 }\end{array}$ & $\begin{array}{l}\text { 三维线框造型、曲面造型、实体造型、特征造型等技术, 通过将几何造型技 } \\
\text { 术融入到石油机械设计制造过程中, 以 SolidEdge、UG 等为设计平台, 建立 } \\
\text { 全参数化三维实体模型, 实现石油专用零件 (如管螺纹、管柱、钻头、钻机 } \\
\text { 底座、卡盘、吊环等) 的设计。 }\end{array}$ \\
\hline 虚拟设计 & $\begin{array}{c}\text { 石油井场虚拟仿真 } \\
\text { 平台 }\end{array}$ & $\begin{array}{l}\text { 通过虚拟仿真技术将勘探、钻井、采油等过程直观地展示出来, 在此过程中 } \\
\text { 开发出 “石油井场虚拟仿真平台”, 解决了石油院校机械专业学生难于到钻 } \\
\text { 井、采油生产现场进行认识、操作与实验的困难, 推广了虚拟现实技术在教 } \\
\text { 学上的应用。 }\end{array}$ \\
\hline 智能设计 & $\begin{array}{l}\text { 智能电动钻机 } \\
\text { 智能控压钻井系统 } \\
\text { Victus }\end{array}$ & $\begin{array}{l}\text { 信息时代的到来让石油行业逐渐向智能化发展, 实现了智能设备的研发, 如 } \\
\text { 智能电动钻机可以优化控制和监测整个钻井过程。 } \\
\text { 应用智能控制、设备自动化等领先的技术, Victus 控压钻井集成了钻机设备, } \\
\text { 用于机器与机器之间的通信, 实时分析井下条件, 并从中心位置快速自动响 } \\
\text { 应。 }\end{array}$ \\
\hline 可靠性设计 & $\begin{array}{l}\text { 高性能测井系统 } \\
\quad \text { 压力容器 } \\
\text { 海底管道回收工具 }\end{array}$ & $\begin{array}{l}\text { 在测井系统研制过程中引入可靠性理念, 建立可靠性模型、进行可靠性预计、 } \\
\text { 故障模式影响及分析。 } \\
\text { 对压力容器的尺寸、强度等因素进行分析,明确压力参数的变化情况,对压力 } \\
\text { 容器设计过程中的随机变量进行严格控制。 } \\
\text { 从海底管道回收工具耐环境、应力-强度、功能及耐久性验证的角度进行可靠 } \\
\text { 性设计, 从而提高系统的固有可靠性。 }\end{array}$ \\
\hline $\begin{array}{l}\text { 机构学与机 } \\
\text { 器人设计 }\end{array}$ & 海洋钻修机 & $\begin{array}{l}\text { 根据海洋钻机的二层台机器人的应用要求, 利用机构学与机器人设计方法进 } \\
\text { 行驱动方式和安装方法的设计和选型。 }\end{array}$ \\
\hline 仿生设计 & PDC 钻头 & $\begin{array}{l}\text { 通过模仿穿山甲的鳞片机构对 PDC 钻头进行仿生学设计, 改变其破岩方式, } \\
\text { 从而避免作业中崩齿、断齿等现象。 }\end{array}$ \\
\hline 创新设计 & 结构防腐蚀设计 & $\begin{array}{l}\text { 采用创新设计的变元法对焊接、螺纹联接、铆接结构以及容器的祄板进行结 } \\
\text { 构设计, 以达到结构防腐的功能。 }\end{array}$ \\
\hline 优化设计 & $\begin{array}{l}\text { 深井采油管内减速 } \\
\text { 器 }\end{array}$ & $\begin{array}{l}\text { 应用蚁群优化 (ACO) 对石油机械的静态性能 (强度和刚度) 和动态性能 (位 } \\
\text { 移、速度、加速度响应、系统结构固有频率和振型等) 的综合优化问题, 针 } \\
\text { 对这类包括尺寸优化、拓扑优化和性能优化的全局优化问题, ACO 算法所 } \\
\text { 具有的鲁棒性、正反馈并行机制和非确定性的全局搜索策略, 使得这种算法 } \\
\text { 更适合去求解此类问题。 }\end{array}$ \\
\hline
\end{tabular}

(2) 机械工程前沿的 CAE 技术融入到石油特色 课程的教学内容

随着计算机硬件和软件的发展, CAE 作为一种新 型的数值模拟分析技术, 越来越受到工程技术人员的 重视, 在产品的开发过程中, 不仅可以协助工程人员
做产品设计, 还可以保留相关分析结果成为下次设计 的重要依据[10 11]。有限元作为其中一种数值计算法, 以独有的计算优势得到广泛应用, 它所包含的许多模 块皆可用于石油机械领域中。将机械工程前沿的 CAE 技术融入到机械专业课程中进行教授, 所得到的融合 设计方案如表 2 所示。

\section{表 2 先进 CAE 技术与石油装备教学知识点融合设计方案}

\begin{tabular}{|c|c|c|}
\hline $\begin{array}{c}\text { 机械工程前沿 } \\
\text { 的 CAE 技术 }\end{array}$ & $\begin{array}{c}\text { 机械专业课程中石油装 } \\
\text { 备的知识点 }\end{array}$ & 机械工程新知识与石油专业特色课程知识点的融合方法 \\
\hline 结构静力分析 & $\begin{array}{c}\text { 石油钻机井架、海洋钻 } \\
\text { 修机、海洋钻机以及石 }\end{array}$ & $\begin{array}{c}\text { 通过结构静力分析模块进行分析在风载荷、地震载荷作用下的强 } \\
\text { 度、刚度, 判断各部件是否满足安全性要求, 从而保证了石油装备 }\end{array}$ \\
\hline
\end{tabular}




\begin{tabular}{|c|c|c|}
\hline & 油机械设备的零部件。 & 设计的可靠性和适应性。 \\
\hline $\begin{array}{l}\text { 模态分析 } \\
\text { 谐响应分析 } \\
\text { 瞬态动力分析 } \\
\text { 谱分析 }\end{array}$ & $\begin{array}{l}\text { 钻柱接头与井下工具优 } \\
\text { 化设计 } \\
\text { 发动机、压缩机、柱塞 } \\
\text { 泵等各类旋转机构的故 } \\
\text { 障诊断 } \\
\end{array}$ & $\begin{array}{l}\text { 模态可研究分析钻柱、泵的子频率及模态, 谐响应可分析其共振特 } \\
\text { 性, 瞬态动力分析和谱分析可分别在时域和频域范围内研究各装备 } \\
\text { 的响应特性, 从而全面把握结构的振动特性。 }\end{array}$ \\
\hline $\begin{array}{l}\text { 瞬态动力分析 } \\
\text { 显式动力学分 } \\
\text { 析 }\end{array}$ & $\begin{array}{c}\text { PDC 钻头以及钻柱 } \\
\text { 高压水射流破岩 }\end{array}$ & $\begin{array}{l}\text { Ansys 软件可以有效地完成瞬态动力分析, 对钻柱的动力学参数破 } \\
\text { 岩效果动态变化仿真, 对于 PDC 钻头的优化设计具有指导意义。 } \\
\text { 可以利用显式动力学强大的 3D 流固耦合功能进行分析高压水射流 } \\
\text { 破岩机理 }{ }^{[12]} \text { 。 }\end{array}$ \\
\hline $\begin{array}{l}\text { 非线性结构静 } \\
\text { 力分析 } \\
\text { 动力学分析 } \\
\text { 运动学分析 } \\
\text { 随机振动响应 } \\
\text { 分析 }\end{array}$ & $\begin{array}{l}\text { 起重桅杆 } \\
\text { 挂桥油气管线、埋地油 } \\
\text { 气管线 } \\
\text { 钻采地面配套工程建设 } \\
\text { 装备 }\end{array}$ & $\begin{array}{l}\text { 通过非线性结构静力学分析进行起重桅杆强度与稳定性的分析。 } \\
\text { 采用动力学分析和运动学分析对挂桥油气管线、埋地油气管线进行 } \\
\text { 优化设计。 } \\
\text { 随机振动响应可以对钻采地面配套工程建设的挖掘机动力臂结构 } \\
\text { 进行分析。 }\end{array}$ \\
\hline $\begin{array}{c}\text { 流体动力学分 } \\
\text { 析 }\end{array}$ & $\begin{array}{l}\text { 钻井液混合器 } \\
\text { 新型油水分离器 } \\
\text { 海洋立管 }\end{array}$ & $\begin{array}{l}\text { 应用流体动力学技术对钻井液混合器的喷嘴及混合腔内部的流程 } \\
\text { 进行镜像数字模拟, 对喷嘴结构进行优化设计。 } \\
\text { 充分运用流体动力学技术能够有效的得出油水分离中油的体积与 } \\
\text { 螺旋流道的关系, 并提升此设备的使用性能。 } \\
\text { 将有限元耦合技术同流体动力学技术充分的结合, 能够有效模拟分 } \\
\text { 析涡激振动现象在立管中的影响, 以及分析其同海浪之间的关系。 }\end{array}$ \\
\hline
\end{tabular}

（3）机械工程前沿的制造方法融入到石油特色 课程的教学内容
将机械制造前沿技术融入到石油特色课程的设 计方案如表 3 所示。

\section{表 3 先进制造技术与石油装备教学知识点融合设计方案}

\begin{tabular}{|c|c|c|}
\hline $\begin{array}{c}\text { 机械工程前沿 } \\
\text { 制造技术 }\end{array}$ & $\begin{array}{c}\text { 机械专业课程中石油 } \\
\text { 装备知识点 }\end{array}$ & 机械制造新知识与石油专业特色课程知识点的融合方法 \\
\hline $\begin{array}{c}\text { 机器人及自动 } \\
\text { 化技术 }\end{array}$ & $\begin{array}{c}\text { 自动化修井机 } \\
\text { 射孔枪自动装弹系统 } \\
\text { 海洋钻井用折臂抓管 } \\
\text { 机器人 }\end{array}$ & $\begin{array}{l}\text { 将机器人及自动化技术融入到石油装备领域修井机、射孔枪以及折臂抓管 } \\
\text { 机器人的设计制造中, 通过不断的技术创新, 提高石油机械设备的自动化 } \\
\text { 程度。 }\end{array}$ \\
\hline 智能化技术 & 智能巡检机器人 & $\begin{array}{l}\text { 将智能化技术融入到巡检机器人的设计制造过程中, 通过智能控制对所需 } \\
\text { 检测的开关柜进行检测, 利用传感元件进行信息处理, 并将处理信息存储 } \\
\text { 在无人服务平台, 以供平台的工作人员进行访问。 }\end{array}$ \\
\hline $\begin{array}{l}\text { 虚拟化技术 } \\
\text { 热处理技术 }\end{array}$ & $\begin{array}{c}\text { YG225 游车大钩的铸 } \\
\text { 造 }\end{array}$ & $\begin{array}{l}\text { 应用虚拟化技术进行对 YG225 大钩进行分析、规划及虚拟装配, 在技术 } \\
\text { 的协助下, 及时发现生产作业中存在的质量缺陷, 并通过热处理技术进行 } \\
\text { 自动调控热处理流程, 进而实现对精密构件的无氧型维护。 }\end{array}$ \\
\hline $\begin{array}{l}\text { 先进成形技术 } \\
\text { 快速原型制造 } \\
\text { 技术 }\end{array}$ & 牙轮钻头的牙掌 & $\begin{array}{l}\text { 采用 HRP 系列 LOM 快速成型系统制造牙轮钻头的牙掌, 通过此 RP 制 } \\
\text { 件, 设计者可以对整个部件的几何结构等性能参数进行优化 }{ }^{[13]} \text { 。 }\end{array}$ \\
\hline 数控机床技术 & 特殊管螺纹 & $\begin{array}{l}\text { 通过对加工螺纹新方法的探索, 各种石油油管特殊螺纹进行受力分析和几 } \\
\text { 何计算, 应用现有数控机床, 尽量保持车削螺纹时, 刀具切削力相等, 从 } \\
\text { 而减少刀具发颤, 有效地提高了螺纹加工精度和生产效率。 }\end{array}$ \\
\hline
\end{tabular}




\begin{tabular}{|c|c|c|}
\hline 检测监控技术 & $\begin{array}{l}\text { 抽油井 } \\
\text { 螺杆洜井 } \\
\text { 电潜葲油井 }\end{array}$ & $\begin{array}{l}\text { 采用检测监控技术对抽油井、螺杆百井、电潜百井的控制器实时采集油井 } \\
\text { 的油压、油温、套压、负荷进行监控, 以便油气生产的安全。 }\end{array}$ \\
\hline $\begin{array}{l}\text { 金属 3D 打印 } \\
\text { 技术 } \\
\text { CNC 铣削技术 }\end{array}$ & $\begin{array}{l}\text { 天然气管道 } \\
\text { 压力容器缸 } \\
\text { 连接器 } \\
\text { 井下工具 }\end{array}$ & $\begin{array}{l}\text { 将金属 3D 打印的金属增材制造技术融入到天然气管道、连接器以及井下 } \\
\text { 工具的设计制造过程中。 } \\
\text { 压力容器缸的原型由金属 3D 打印和 CNC 铣削的组合制成, 3D 打印解决 } \\
\text { 方案比其前代制作工艺更加高效, 并且省去了耗时的维护程序。 }\end{array}$ \\
\hline
\end{tabular}

（4）机械工程前沿检测技术融入到石油特色课 程的教学内容
将机械工程先进检测技术融入到石油机械特色 课程的设计方案如表 4 所示。

\section{表 4 先进检测技术与石油装备教学知识点融合设计方案}

\begin{tabular}{|c|c|c|}
\hline $\begin{array}{l}\text { 机械工程先进检 } \\
\text { 测技术 }\end{array}$ & $\begin{array}{l}\text { 机械专业课程中石 } \\
\text { 油装备的知识点 }\end{array}$ & 机械先进检测技术与石油专业特色课程知识点的融合方法 \\
\hline 应变测试技术 & $\begin{array}{l}\text { 井架承载能力评估 } \\
\text { 抽油机结构强度 } \\
\text { 套管失效分析 }\end{array}$ & $\begin{array}{l}\text { 应用应变测试技术对井架升沉情况、抽油机连接孔及产层套管的应 } \\
\text { 力、应变进行实时监控, 并及时进行维护和修理。 }\end{array}$ \\
\hline $\begin{array}{l}\text { 测径检测技术 } \\
\text { 泄漏检测技术 } \\
\text { 漏磁通检测技术 }\end{array}$ & 石油管道 & $\begin{array}{l}\text { 测径检测技术主要用于管道因外力引起的几何变形, 确定变形具体 } \\
\text { 的位置。 } \\
\text { 泄漏检测技术对石油管道是通过测压装置检测其内部压力判断其泄 } \\
\text { 露位置, 或通过以声波辐射的方法进行检测并确定泄露位置。 } \\
\text { 漏磁通检测技术能检测出管道内、外腐蚀产生的体积型缺陷, 对检测 } \\
\text { 环境要求低, 可用于输油和输气管道, 可以判断其涂层状况。 }\end{array}$ \\
\hline 防腐检测技术 & $\begin{array}{c}\text { 石油钻井机 } \\
\text { 抽油原 }\end{array}$ & $\begin{array}{l}\text { 应用防腐检测技术对石油钻井机、抽油泵的腐蚀情况进行测厚检测 } \\
\text { 以及电阻探伤监测, 从而保护其设备的正常使用。 }\end{array}$ \\
\hline 声发射检测技术 & 压力容器 & $\begin{array}{l}\text { 声发射检测技术是根据内部结构来判断内部损伤程度的一种新型的 } \\
\text { 动态无损检测技术, 它能够直接检测出压力容器材料内部缺陷, 一方 } \\
\text { 面降低了恶性事故的发生, 另一方面大大缩短压力容器的检验周期。 }\end{array}$ \\
\hline TOFD 检测技术 & 薄壁堆焊层裂纹 & $\begin{array}{l}\text { TOFD 检测技术是一种利用超声波衍射时间差进行检测的无损检测 } \\
\text { 方法, 将此检测技术融入到石油装备领域进行焊层的裂纹的检测。 }\end{array}$ \\
\hline
\end{tabular}

(5) 机械工程新材料知识融入到石油特色课程 的教学内容
机械工程新材料知识融入石油院校机械专业特 色课程的教学内容设计方案如表 5 所示。

\section{表 5 新材料技术与石油装备教学知识点融合设计方案}

\begin{tabular}{|c|c|c|}
\hline $\begin{array}{c}\text { 机械工程新材料知 } \\
\text { 识点 }\end{array}$ & $\begin{array}{c}\text { 机械专业课程中石油 } \\
\text { 装备的知识点 }\end{array}$ & 机械新材料与石油专业特色课程知识点的融合方法 \\
\hline 纳米材料 & $\begin{array}{l}\text { 润滑油添加剂 } \\
\text { 脱硫剂 }\end{array}$ & $\begin{array}{l}\text { 应用纳米材料制作的润滑添加剂、脱硫剂应用于油田各种气 } \\
\text { 态、液态物中, 可以高效地将硫醇转化为二硫化物。 }\end{array}$ \\
\hline $\begin{array}{l}\text { 气凝胶-相变微胶囊 } \\
\text { 复合隔热材料 }\end{array}$ & $\begin{array}{l}\text { 随钻测量电子设备 } \\
\text { 蒸汽管线 } \\
\text { 地热管线 }\end{array}$ & $\begin{array}{l}\text { 结合气凝胶的隔热和相变微胶囊的吸热不升温的特点, 可以不 } \\
\text { 改变原有工作结构的情况下, 使蒸汽管线、地热管线保温, 广 } \\
\text { 泛的应用于随钻测量电子设备的隔热保护。 }\end{array}$ \\
\hline 功能梯度材料 & $\begin{array}{l}\text { 钻头、钻杆节头、泥 } \\
\text { 浆㬌缸套、抽油㫤活 } \\
\text { 塞、射孔弹表面设计 }\end{array}$ & $\begin{array}{l}\text { 通过调节梯度材料的结构、组成、配比等, 能够制备硬度更高、 } \\
\text { 抗磨蚀性能更好的材料, 用于制造超强钻头、钻杆节头、泥浆 } \\
\text { 原缸套、抽油泵活塞, 从而提高它们的硬度和耐磨性能。 }\end{array}$ \\
\hline
\end{tabular}




\begin{tabular}{|c|c|l|}
\hline \multirow{2}{*}{ 自愈合聚合物材料 } & $\begin{array}{c}\text { 自愈合固井水泥 } \\
\text { 自愈合封堵材料 } \\
\text { 自反应钻井液 } \\
\text { 封隔器 }\end{array}$ & $\begin{array}{l}\text { 应用自愈合聚合物材料作为井下流体的化学添加剂, 根据井下 } \\
\text { 条件的变化作出反应或者变形, 从而实现凝固或者封堵作用。 } \\
\text { 而且此材料还可以作为封隔器等工件的构成材料, 增加封隔器 } \\
\text { 的强度和使用寿命。 }\end{array}$ \\
\hline $\begin{array}{c}\text { 钛纳米高分子合金 } \\
\text { 新材料 }\end{array}$ & $\begin{array}{l}\text { 海上石油平台 } \\
\text { 油管防腐 } \\
\text { 台润、抗渗透、自清洁和导静电功能, 将其应用于海上石油平 } \\
\text { 境下的防腐维护。钢结构设备, 有助于石油平台和油管在特种环 }\end{array}$ \\
\hline
\end{tabular}

\section{4.融合前沿知识的特色课程教学实践}

为检验本文教学方法及设计方案的实用效果, 笔 者在西安石油大学 2015、2016 级机械专业开展了新 形势下机械特色专业课程案例式教学系统的实践, 取 得了良好的效果。

从学生对教学系统的接受程度来分析, 将机械工 程学科前沿知识融入到石油机械课程的教学内容更 加能激发学生的兴趣, 能使学生明确自己所学的机械 知识在石油行业的应用, 并能更加系统化地掌握机械 工程学科和石油装备前沿知识。从课程考核结果分析 来看, 在学时学分没有增加的情况下, 学生掌握了更 全面的知识点, 而且学生应用新知识和新技术解决复 杂工程问题的能力也得到了提高, 达到了教学质量提 升的目的。

\section{5.结论}

本文提出了将机械工程前沿知识融入石油机械 专业特色课程的案例式教学方法, 并设计了系统性的 教学内容。该教学方法不增加学时学分, 又将机械工 程学科与石油特色课程的前沿知识巧妙融合。该方法 可使学生在学习的过程中掌握更多新的知识, 有效解 决学时学分紧张的问题, 同时还达到了理论知识与实 际工程问题相结合的教学目标。从实践结果看, 学生 对专业课程新知识掌握和运用的能力有所提高, 对石 油机械装备从设计制造到应用的过程更加明确, 教学 效果良好, 说明本文提出的方法是有效且可行的。

\section{References}

[1] Wen, B.Q., Ma, C.H., Yuan, C.F., Peng, X. (2021) Research and Exploration of Integrating 3D Modeling into Mechanical Surveying and Mapping Practice Teaching Mode. Modern Vocational Education, 7: 96-97.

[2] Shu, S.R., Liu, Y.P. (2021) Teaching Reform Strategy of "Mechanical manufacturing equipment design" Course under the Background of Emerging Engineering Education. Internal Combustion Engine \& Parts, 42: 254-255.

[3] Zhao, M., Li, C., (2021) Teaching Reform and
Practice of Mobile Information under the Background of Engineering Education--Taking Process Fluid Machinery Course as an Example. University Education, 10: 43-45+58.

[4] Gao, P., Zhuo, Y. (2021) Teaching reform of "Internet plus initiative" AR technology, AutoCAD and mechanical drawing theory--Comment on "Modern Engineering Graphics". Journal of Machine Design, 38: 159.

[5] Zhang, S., Liu, L.M., Chen, Y. (2021) Teaching reform of industrial design specialty under the background of new engineering--Taking mechanical design foundation course as an example. Educational Informatization Forum, 5: 75-76.

[6] Dong, X.Q. (2021) 3D Printing Technology Promotes Higher Vocational Teaching Reform and Deep Integration of Courses. Computer Knowledge and Technology, 17: 92-93+105.

[7] Han, D.Y., Kong, X.X., Luo, H. (2019) Reform of Teaching System Based on Virtual Simulation Platform of Oil Well Field. Education Modernization, 6: 25-26+43.

[8] Li, Z., Wu, S.Y. (2019) Petroleum Machinery Professional Teaching Practice based on Unity 3D. China Educational Technology \& Equipment, 33: 32-34.

[9] Simon S. et al. (2021) Leading pedagogical reform: Australian principals tell their stories. International Journal of Leadership in Education, 24: 266-289.

[10] Kwek D. et al. (2020) Policy and pedagogical reforms in Singapore: Taking stock, moving forward. Asia Pacific Journal of Education, 40: 425-432.

[11] Wan, Z.G., Dou, Y.H., Zheng, J. (2019) Reform and Exploration of Graduation Design of Mechanical Design Manufacturing and Automation Specialty under Engineering Education Professional Certification. Light Industry Science and Technology, 35: 173-174.

[12] An, C., Wei, D.F. (2020) Application of Secondary Development Example Teaching in the Course on 
Finite Element Analysis Software Application of Petroleum Machinery. Education Teaching Forum, 45: 293-294.

[13] Chen, Y.H., Wu, X.D. (2012) Discussion on Teaching Reform of Basic Course of Mechanical Manufacturing Technology Based on Characteristics of Petroleum Machinery. Science and Technology Innovation Herald, 23: 146+148. 